\title{
STRATEGI GURU PENDIDIKAN AGAMA ISLAM DALAM MENANGANI ANAK INKLUSI DI SD HJ ISRIATI BAITURAHMAN 1 SEMARANG TAHUN 2018
}

\author{
${ }^{1}$ Azzah Nor Musthofiyah, ${ }^{2}$ Hidayatus Sholihah \\ ${ }^{12}$ FAI Universitas Islam Sultan Agung (UNISSULA) Semarang \\ 1 azzahnooor.xi.a4.1213@gmail.com \\ 2hida@unissula.ac.id
}

\begin{abstract}
This study aims to describe how the strategy of Islamic Education teachers in handling inclusion children in SD Hj Isriati Baiturahman 1 Semarang which consists of: planning, learning process, and evaluation or handling carried out by the Islamic Religious Education teacher right when studying at SD Hj Isriati Baiturahman 1 Semarang.

The research conducted by the author is qualitative research. The research subjects were Islamic Education teachers who taught inclusion children from class I to class VI and collaborated with Counseling Guidance teachers. While the object of this research is the right strategy for inclusion children in Islamic Education subjects. Data is carried out through observation, interviews, documentation. The validity of the data used is Triangulation. Analysis of the data used is Reduction, Display, Conclusing Drawing.

This research is intended to answer the problem: How is the strategy of Islamic Education teachers in handling inclusion children in SD Hj Isriati Baiturahman 1 Semarang. This study shows that: (a) planning of personal records is carried out to Islamic Religious Education teachers with data obtained from homeroom teachers who are followed up by Counseling Guidance teachers. This makes it easy for Islamic Education teachers to plan treatment strategies before learning takes place for inclusion children with various characteristics in different classes. (b) For the implementation of learning carried out in various classes, Islamic Education teachers are assisted by Shadow or accompanying teachers. (c) the handling or evaluation of the study that the strategies of the four Islamic Education teachers have strategies that vary according to the level of characteristics of the inclusion child (Slow Learner, ADHD, mentally disabled).
\end{abstract}

Keywords : inclusion, Islamic Studies Teacher, strategy

\begin{abstract}
ABSTRAK
Penelitian ini bertujuan untuk mendeskripsikan bagaimana strategi guru Pendidikan Agama Islam dalam menangani anak inklusi di SD Hj Isriati Baiturahman 1 Semarang yang terdiri dari : perencanaan, proses pembelajaran, dan evaluasi atau penanganan yang dilakukan oleh guru Pendidikan Agama Islam yang tepat saat pembelajaran di SD Hj Isriati Baiturahman 1 Semarang.

Penelitian yang dilakukan penulis merupakan penelitian kualitataif. Subjek penelitian tersebut yaitu guru Pendidikan Agama Islam yang mengajar anak inklusi dari kelas I hingga kelas VI dan bekerjasama dengan guru Bimbingan Konseling. Sedangkan objek penelitian ini adalah strategi yang tepat untuk anak inklusi pada mata pelajaran Pendidikan Agama Islam. Data dilakukan melalui observasi, wawancara, dokumnetasi. Validitas data digunakan ialah Triangulasi. Analisis data yang digunakan ialah Reduksi, Display (penyajian data), Conclusing Drawing (penarikan kesimpulan).
\end{abstract}


Penelitian ini dimaksudkan untuk menjawab permasalahan : Bagaimana strategi guru Pendidikan Agama Islam dalam menangani anak inklusi di SD $\mathrm{Hj}$ Isriati Baiturahman 1 Semarang. Kajian ini menunjukkan bahwa : (a) perencanaan Catatan pribadi tersebut dilakukan kepada guru Pendidikan Agama Islam dengan data didapatkan dari wali kelas yang di follow up oleh guru Bimbingan Konseling. Hal itu memudahkan guru Pendidikan Agama Islam merencanakan strategi penanganan sebelum pembelajaran berlangsung terhadap anak inklusi dengan berbagai karakteristik pada kelas yang berbeda-beda. (b) Untuk pelaksanaannya pembelajarannya yang dilakukan di berbagai kelas, guru Pendidikan Agama Islam dibantu oleh Shadow atau guru pendamping (c) penanganan atau evaluasi dari penelitian tersebut bahwa strategi dari keempat guru Pendidikan Agama Islam tersebut memiliki strategi yang bervariasi sesuai dengan tingkat karakteristik anak inklusi (Slow Learner, ADHD, Tuna Grahita) tersebut.

Kata Kunci : Inklusi, Guru PAI, Strategi 


\section{A. PENDAHULUAN}

Manusia diciptakan oleh Sang
Maha Kuasa dengan berbagai
perbedaan. Perbedaan itulah menjadi ciri
khas yang mendukung manusia tersebut
bisa menjadi lebih percaya diri untuk
berpotensi dan berusaha. Perbedaan
itulah yang disebut individual difference
(Hosnan, 2016: 79).

Manusia juga memiliki sebuah kelebihan dan kekurangan. Kelebihan tersebut bisa dijadikan nilai positif untuk mendorong manusia berprestasi sesuai kelebihannya. Namun bagaimana dengan seseorang yang memiliki kekurangan dalam bidang tertentu dan dianggap sebagai anak yang berbeda dari anak normal pada umumnya.

Keluarga merupakan lingkungan yang paling dekat dengan proses interaksi, namun dalam ranah ini sekolah merupakan pendidikan kedua setelah ranah keluarga. Sekolah ini merupakan lembaga pendidikan yang memiliki tujuan yang jelas (Tafsir, 2011: 132).

Selain itu peranan sekolah sangat penting dalam perkembangan intelegensi seorang anak, di sekolah-sekolah umum biasanya hanya mampu menerima siswa siswi yang setara namun masih ada anak inklusi yang harus diberi pembelajaran yang khusus terkait kegiatan belajar mengajar. Anak inklusi ialah anak yang membutuhkan perubahan dari pelayanan, metode dan tugas-tugas sekolah yang dikhususkan untuk mengembangkan kemampuan secara maksimal yaitu mereka yang berbeda dengan anak normal memiliki salah satu ciri-ciri perilaku emosional, sosial, neuromuskular, fisik, kemampuan berkomunikasi, kemampuankemampuan sensorik, mental, maupun kombinasi dua atau lebih dari ciri-ciri tesebut (Mangunsong, 2009: 4).
Salah satu argumen pihak yang menolak inklusi yaitu orang tua, guru umum dan guru pendidikan lebih puas kepada pendidikan khusus, guru umum tidak mampu menangani anak-anak inklusi, ketidakmampuan melihat kenyataan di lapangan. Di sekolah umum guru cenderung tidak tertarik dengan kehadiran anak-anak inklusi karena dirasa anak-anak inklusi memberikan beban kepada guru yang mengampu berbagai mata pelajaran dan perhatian tersebut tidak cukup untuk terpenuhi di kelas-kelas umum (Mangunsong, 2009: 23-24).

Namun faktanya di sekolah yang penulis teliti yaitu $\mathrm{SD} \mathrm{Hj}$ Isriati Baiturahman 1 Semarang yang notabenya terkenal sebagai sekolah berbasis Islami dan umum, guru Pendidikan Agama Islam (PAI) mampu memberikan pendidikan yang layak kepada anak-anak inklusi terutama dalam bidang keagamaan untuk meningkatkan keimanan dengan meyakini ciptaan Sang Maha Kuasa tidak ada yang sia-sia dan berusaha mendekatkan diri kepada Sang Maha Kuasa sehingga mereka mampu percaya diri dalam menghadapi persaingan di era globalisasi ini.

Dalam hal ini sangat diperlukan sebuah strategi yang tepat untuk anakanak inklusi karena berbeda dengan anak normal pada umumnya. Strategi pembelajaran sendiri menurut Jamil Suprihatiningrum dalam bukunya yang berjudul Strategi Pembelajaran Teori \& Aplikasi bahwa strategi pembelajaran ialah suatu rancangan yang bertahap dalam proses pembelajaran berupa tindakan guru demi mencapai tujuan (Suprihatiningrum, 2016: 153).

Strategi pembelajaran yang tepat sangat dibutuhkan peran seorang guru, 
terutama dalam lingkup keagamaan, guru Pendidikan Agama Islam sendiri menurut Ramayulis dalam bukunya yang berjudul Metodologi Pendidikan Agama Islam ialah seseorang yang melakukan bimbingan demi tercapainya tujuan yang diinginkan sesuai dengan ajaran Islam dengan sasaran peserta didik secara Islami menurut ruang lingkup kependidikan (Ramayulis, 2005: 50).

SD $\mathrm{Hj}$ Isriati Baiturahman 1

Semarang memberikan pelayanan bidang akademik yang baik hingga memiliki program unggulan yang disebut kelas Akslerasi. Selain itu juga terdapat pelayanan inklusif dimana penempatan kelas-kelas untuk anak inklusi di kelas biasa atau reguler yaitu kelas 1-6 anak inklusi ditempatkan diberbagi kelas bukan dikelompokkan dalam satu kelas dan anak-anak inklusi mampu berbaur dengan temantemannya. Berbeda dengan sekolah lainnya sekolah ini mampu menerima dan membantu anak tersebut dalam pembelajaran yang memadai hingga LULUS. Dalam hal ini keterlibatan guru PAI sangat penting karena selain membekali anak dengan pengetahuan intelektual peserta didik saja atau pengetahuan Agama, namun juga berusaha membentuk jiwa dan batin Agama yang baik. Lingkungan sekolah ini terkhusus guru akan selalu membimbing peserta didiknya dalam proses belajar dapat tumbuh menjadi Hamba Allah yang bertaqwa kepada Allah SWT dan mendapat perubahan yang positif.

Bagaimana strategi seorang guru PAI dalam menangani anak inklusi pada sebuah pembelajaran Pendidikan Agama Islam agar pembelajaran menjadi sama dan tanpa memberi beban kepada anakanak inklusi dan mereka bisa berbaur dengan teman-teman umum di kelasnya, walaupun anak-anak inklusi memiliki banyak perbedaan dengan anak normal pada umumnya baik dalam segi mental, intelegensi, dan lain lainnya.

\section{B. METODE PENELITIAN}

Penelitian ini menggunakan jenis penelitian lapangan (field research) yaitu penelitian yang dilakukan secara langsung di lapangan tepatnya di SD Hj Isriati Baiturahman 1 Semarang. Penelitian ini bersifat deskriptif kualitatif, yaitu penelitian dengan menjelaskan keadaan sebenarnya. Sehingga pengumpulan data dan informasinya berupa observasi, wawancara, dokumentasi dan analisis data terhadap pihak yang terkait. Wawancara langsung kepada guru yang bersangkutan yaitu empat guru pengampu mata pelajaran PAI di kelas yang terdapat anak inklusi tersebut dari kelas I hingga kelas VI, mencakup strategi penanganan dalam pembelajaran yang dilakukan oleh masing-masing guru pengampu PAI di kelas tersebut.

\section{HASIL PENELITIAN DAN PEMBAHASAN}

\section{Perencanaan}

Kurikulum yang digunakan sama dengan anak normal, dengan KKM yang dibuat 60, akan tetapi di dalam proses pembelajaran tergantung oleh kebijakan masing-masing guru yang mengampu di kelasnya. Hal itu dibuktikan dengan adanya Rencana Perangkat Pembelajaran yang sama di kelas yang satu dengan yang lainnya sama.

Catatan pribadi tersebut dilakukan kepada guru PAI dengan data didapatkan dari wali kelas yang di follow up oleh guru BK. Hal itu 
memudahkan guru PAI merencanakan strategi penanganan sebelum pembelajaran berlangsung terhadap anak inklusi dengan berbagai karakteristik pada kelas yang berbeda-beda berorientasi pada kehidupan sehari-hari yaitu teori sekaligus praktek (wawancara tanggal 9 januari 2018)

\section{Pelaksanaan}

Pada pelaksanaan yang dilakukan oleh keempat guru PAI mengenai strategi guru PAI dalam menangani anak inklusi, di kelas dengan melakukan :

a. Pendahuluan pembelajaran

Seluruh guru PAI membuka pelajaran dengan membaca basmallah dilanjutkan salam dan do'a mencari Ilmu "Robbizidnii ilman Warzuqnii Fabmaa" dan membaca surat Al-Fatihah sekitar 10 menit.

b. Inti pembelajaran

$$
\begin{array}{cc} 
& \text { Inti pembelajaran pada } \\
\text { mata } & \text { pelajaran }
\end{array}
$$

dilaksanakan 120 menit yaitu 2 jam pertemuan. Kegiatan inti menggunakan kurikulum 2013 meliputi mengamati, menanya, mengeksplor atau menalar, mengasosiasi atau mencoba, komunikasi atau demonstrasi.

Kelas I A pada pelajaran

PAI dengan materi Cinta Nabi dan Rasul dan terdapat anak inklusi bernama Hazel Muhammad Zidni kategori ADHD sebagai pengampu pelajaran PAI di kelas tersebut yaitu Bapak Riklan, S.Pd., menjelaskan materi Cinta Nabi dan Rasul dengan sabarnya beliau mengajarkan pelajaran tersebut sesekali melontarkan pertanyaan kepada seluruh siswa namun tidak sama sekali menangani zidni, karena zidni tidak bisa tenang, tidak bisa dikendalikan, sering jerit-jerit di kelas dan lari-lari sering kali zidni dalam pembelajaran tersebut dibantu oleh Shadow namun dia tidak bisa memperhatikan sepernuhnya hanya menggambar dan duduk dibelakang bersama Shadow, penanganan tersebut benarbenar diserahkan oleh Shadow dan belum bisa mengamati, menanya, mengeksplor atau menalar, mengasosiasi atau mencoba, komunikasi atau demonstrasi secara mandiri (Oservasi tanggal 16 januari 2018)

Kelas II melakukan pembelajaran di luar kelas tepatnya di depan ruang guru pada materi membaca dan menulis Al-Qur'an, disitu terdapat anak inklusi bernama M. Hisyam Al-Syahbani dengan kategori Tuna grahita sedang dan guru pengampunya yaitu Bapak Ahmad Syaiku, S.Pd.I., satu persatu peserta didik maju secara face to face, termasuk anak inklusi pada saat maju untuk menghafalkan ayat-ayat AlQur'an berupa surat-surat tersebut, berfokus pada M. Hisyam Al Syahbana, ia menghafal surat An-Nas, dia bisa menghafal secara lancar namun ketika ditanya huruf pertama (materi huruf hijaiyah bersambung) dari surat An-Nas ia tidak bisa menjawab, setelah 
itu dijelaskan secara perlahan oleh Bapak Syaiku secara empat mata, saat pembelajaran tersebut dilakukan dengan sengaja beliau mencampur dia dengan teman-temannya. Dia mampu mengamati, mengasosiasi atau mencoba, komunikasi atau demonstrasi materi namun kurang aktif dan belum bisa pada tahap menanya (Observasi tanggal 10 januari 2018).

\section{kelas IV A Ananta}

Pratama Putra dengan kategori Tuna grahita sedang dengan mata pelajaran BTQ materi tajwid yaitu idghom bigunnah dan idzhar halqi. Ibu Nurul Syamsiyah, S.Ag., sebagai pengampu mata pelajaran PAI, di kelas tersebut. Ketika beliau menjelaskan seluruh siswa mengamati dan ada sebagian siswa normal lainnya aktif tak jarang yang menanya, ketika beliau memberikan tugas dengan mencari contoh hukum bacaan tersebut di Al-Qur'an Ananta Pratama Putra hanya mampu menulis pertanyaannya saja di papan tulis namun belum bisa mengeksplor atau menalar, mengasosiasi atau mencoba, komunikasi, menulisnya pun masih dibantu oleh Shadow (observasi tanggal 23 januari 2018)

Kelas V A Aburrahman

Sudia Hamami dengan kategori Tuna grahita sedang Bapak Kodliyaka, S.Pd., pada materi PAI yaitu Indahnya Saling Menghargai ia ditempatkan pada bangku yang ada anak pintarnya, beliau sebelum mengajar, anak-anak diberi kesempatan untuk membaca buku sebelum beliau menjelaskan, ia sudah mampu mengamati, mengeksplor atau menalar, mengasosiasi atau mencoba, komunikasi atau demonstrasi diantu dengan teman-temannya sosialisasinya juga baik, namun belum bisa menanya (observasi tanggal 24 januari 2018).

c. Penutup pembelajaran Keempat guru PAI memberikan kesimpulan dari materi pembelajaran tersebut serta menyampaikan rencana pembelajaran pada pertemuan berikutnya dan menutup pembelajaran dengan mengucapkan do'a penutup majelis taklim "Subbanaka Allahumma wa bihamdika asybadu an laa-ilaaha illaa Anta astaghfiruka wa-atunbu ilaik".

\section{Evaluasi pembelajaran}

Evaluasi disini bertujuan mengetahui keberhasilan atau pemahaman anak inklusi terhadap materi yang disampaikan oleh guru PAI setelah guru menerapkan beberapa strategi tersebut dalam mengangani anak inklusi di kelas.

Pada Hazel Muhammad Zidni dengan kategori ADHD tidak bisa dibiarkan secara mandiri untuk proses belajar mengajar, dia masih butuh Shadow sepenuhnya.

Pada M. Hisyam Al-Syahbani dengan kategori Tuna grahita sedang mampu mengikuti pelajaran dengan ketentuan harus dijelaskan hingga ia mampu, karena belum 
bisa menalar dengan huruf pertama surat An-Nas itu apa.

Pada Pratama Putra dengan kategori Tuna grahita sedang mampu mengikuti pelajaran bisa seperti menulis dan cerita dalam kehidupan sehari-hari dengan dorongan untuk mengerjakan dan memperhatikan walaupun hanya sebentar dan mudah untuk berkomunikasi jadi sering melakukan tanya jawab secara intens, namun masih tidak bisa mengerjakan tugas secara sempurna.

Pada Aburrahman Sudia Hamami dengan kategori Tuna grahita sedang mampu berbaur dan sangat memperhatikan, rajin, suka pelajaran menghafal, namun kurang aktif.

Menurut hasil wawancara penulis kepada guru BK, guru PAI, ada faktor pendukung dan penghambat. Mengenai faktor pendukung, adapun pendapat guru BK yaitu Adanya kerjasama dari berbagai pihak, adanya poin-poin hitam diatas putih yaitu kesepakatan dari orang tua diatas materai yang dilaksanakan yaitu :

a. kesanggupan mengikuti peraturan di sekolah

b. bersedia terapi sesuai kategori (di biro terapi agar emosi bisa terkontrol)

c. orang tua tidak menuntut akademis, dibutuhkan Shadow untuk penanganan di kelas.

d. di kelas VI bersedia tidak ikut UN maka siap menginduk di SLB.

\begin{tabular}{llr}
\multicolumn{1}{c}{ Selain } & adanya & faktor \\
pendukung maka adapula & faktor \\
penghambat, adapun faktor & fang \\
penghambat yang dikemukakan \\
oleh sumber yang sudah penulis
\end{tabular}

interview, terutama faktor penghambat dari guru PAI dalam menangani anak inklusi tersebut sebagai berikut :

Menurut guru BK penghambat dari adanya anak inklusi mengenai perkembangannya ialah dari pihak orang tua tidak bisa diajak kerja sama, terkhusus tidak memahami kondisi anak yang sebenarnya, Banyak tuntutan dari orang tua mengenai akademisi anak.

\section{KESIMPULAN}

Berdasarkan hasil penelitian yang penulis lakukan maka dapat disimpulkan bahwa strategi dari keempat guru PAI tersebut memiliki strategi yang bervariasi sesuai dengan tingkat karakteristik anak inklusi tersebut antara lain :

1. Penanganan dari Bapak Ahmad Syaiku S.Pd.I., selaku pengampu mata pelajaran PAI di kelas II \& VI bahwasanya menggunakan strategi: face to face (yaitu tatap muka secara langsung), empat mata saat menjelaskan materi, memberikan dorongan semampunya sebagai guru yang menangani, memberikan keringanan dalam belajar, serta dibantu oleh Shadow dalam menstransfer materi kepada anakanak inklusi, untuk memahamkan PAI kepada peserta didik dengan mengajarkan teori sekaligus praktek (ada masjid jadi lebih mudah).

2. Penanganan dari Bapak Riklan S.Pd., selaku pengampu mata pelajaran PAI di kelas I \& III bahwasanya menggunakan strategi: sering memutarkan video agar peserta didik terutama anak inklusi bisa diam dan setidaknya bisa fokus, untuk memahamkan PAI kepada anak 
inklusi meminta bantuan sepenuhnya kepada Shadow.

3. Penanganan dari Ibu Nurul Syamsiyah S.Ag., selaku pengampu mata pelajaran PAI di kelas IV bahwasanya menggunakan strategi: cara menjelaskan materi secara detail, bukan hanya teori/ pengetahuan saja yang dikejar yang terpenting juga praktek, untuk memahamkan PAI kepada anak inklusi meminta bantuan sepenuhnya kepada Shadow.

4. Penanganan dari Bapak Kodliyaka S.Pd.I., selaku pengampu mata pelajaran PAI di kelas V bahwasanya menggunakan strategi: penempatan tempat duduk didekatkan dengan temannya yang pintar agar temannya bisa membantu (tutor sebaya), dan pada saat akan ulangan diberi soal plus jawaban sehingga bisa dihafalkan di rumah agar ujian bisa berhasil, untuk memahamkan PAI kepada anak inklusi meminta bantuan sepenuhnya kepada Shadow.

Strategi pembelajaran yang dilakukan keempat guru PAI meliputi strategi pembelajaran langsung, tak langsung, interaktif, empirik, dan mandiri namun meninggalkan strategi pembelajaran tak langsung. 


\section{DAFTAR PUSTAKA}

Kementerian Agama RI, (2012). Al-Qur'an dan Terjemahnya. Bandung: Syamil Qur'an.

Majid, A. (2012). Belajar dan Pembelajaran. Bandung: PT Remaja Rosdakarya Offset.

Hasyim, F. (2015). Kurikulum Pendidikan Agama Islam. Malang: Madani.

Undang-Undang Dasar Negara Republik Indonesia Tahun 1945 dan UndangUndang Republik Indonesia Nomor 24 Tabun 2003 tentang Mabkamah Konstitusi. (2006). Jakarta: Mahkamah Konstitusi Republik Indonesia.

Syahidin. (2009). Moral dan Kognisi Islam. Bandung: CV Alfabeta.

Suprihatiningrum, J. (2016). Strategi Pembelajaran. Jogjakarta: Ar-Ruzz Media.

Majid, A. (2005). Pendidikan Agama Islam Berbasis Kompetensi. Bandung: PT Remaja Rosdakarya Offset.

Undang-Undang Guru dan Dosen. (2012). Yogyakarta: Pustaka Pelajar.

Ramayulis. (2005). Metodologi Pendidikan Islam. Jakarta: Kalam Mulia.

Mangunsong, F. (2009). Psikologi dan Pendidikan Anak Berkebutuhan Khusus Jilid Kesatu. Jakarta: LPSP3 UI.

Aphroditta. (2013). Panduan Lengkeap Orangtua \& Guru Untuk. Anak Dengan Disleksia (kesulitan membaca). Jogjakarta: Javalitera.
Delphie, B. (2009). Psikologi Perkembangan (Anak Berkebutuban Khusus). Yogyakarta: PT Intan Sejati Klaten.

Hamruni. (2009). Strategi Dan ModelModeIPembelajran Aktif Menyenangkan. Yogyakarta: Fakultas Tarbiyah UIN Sunan Kalijaga Yogyakarta.

Sanjaya, W. (2013). Strategi Pembelajaran Berorientasi Standar Proses Pendidik. Jakarta: Prenadamedia.

Sugiarman, M. (2012). Sekolah Inklusi: Konsep Dan Penerapan Pembelajaran. Dalam J. D. Smith, Inclusion, School For All Student (hal. 85-92). Bandung: Nuansa.

Hinz, A. (2014). Inclusion as a 'North Star' and prospects for everyday life. Considerations about concerns, transformations and necessities of inclusion in schools in Germany. REIFOP , 20-21.

Hosnan. (2016). Psikologi Perkembangan Peserta Didik. Bogor: Ghalia Indonesia.

Tafsir, A. (2011). Metodologi Pengajaran Agama Islam. Bandung: PT Remaja Rosdakarya.

Nazir, M. (2014). Metode Penelitian. Bogor: Ghalia Indonesia.

Sugiyono. (2013). Metode Penelitian Pendidikan Pendekatan Kuantitatif, Kualitatif, dan R\&D. Bandung: Alfabeta.

Hamdani. (2011). Strategi Belajar Mengajar. Bandung: Pustaka Setia.

Hawi, A. (2014). Kompetensi Guru Pendidikan Agama Islam. Jakarta: Rajagrafindo Persada.

Forlin, C. (1998). Teachers' Personal Concerns About Including Children 
with a Disability in Reguler Classrooms. Developmental and Physical Disabilities , 15.

Mohammed, N. (2013). Islamic Education, Eco-ethies andCommunity. Springer Science+Business Media Dorstrecht, 137.

SISDIKNAS, U.-U. (2007). UU RI No. 20 Tahun 2003. Jakarta: Sinar Grafika Offset.

Ormrod, J. E. (2008). Psikologi Pendidikan Membantu Siswa Tumbuh dan Berkembang. Jakarta: Erlangga.

Prastowo, A. (2015). Menyusun Rencana Pelaksanaan Pembelajaran (RPP) Tematik Terpadu (Implementasi Kurikulum 2013 untuk SD/MI). Jakarta: Prenamedia Group.

Sugiyono. (2015). Statistika untuk Penelitian. Bandung: Alfabeta.

Gunawan, H. (2014). Pendidikan Islam Kajian Teoritis dan Pemikiran Tokoh. Bandung: PT Remaja Rosdakarya.

Usman, M. U. (2002). Menjadi Guru Profesional. Bandung: PT Remaja Rosdakarya.

Siberman, M. L. (2013). Active Learning (101 cara belajar siswa aktif). Bandung: Nuansa Cendekia.

Dirman, d. (2014). Karakteristik Peserta Didik. Jakarta: PT Rineka Cipta.

Arikunto, S. (2012). Dasar-Dasar Evaluasi Pendidikan. Jakarta: Sinar Grafika Offset.

SM, I. (2002). Strategi Pembelajaran Agama Islam Berbasis PAIKEM. Semarang: RaSAIL Media Group.
Halmar, M. (2008). Strategi Belajar Mengajar. Semarang: Unissula Press.

Hamzah, A. (2014). Perencanaan dan Strategi Pembelajaran Matematika. Jakarta: PT Raja Grafindo Persada.

Daradjat, Z. (2014). Metodik Khusus Pengajaran Agama Islam. Jakarta: PT Bumi Aksara.

Bahasa, P. (2013). Kamus Besar Bahasa Indonesia Pusat Bahasa. Jakarta: PT Gramedia Pustaka Utama.

Rohani, A. (2010). Pengelolaan Pengajaran. Jakarta: PT Rineka Cipta.

Djamarah, S. B. (2013). Strategi Belajar Mengajar. Jakarta: PT Rineka Cipta.

RI, K. A. (2012). Al-Qur'an dan Terjemahnya. Bandung: Syamil Qur'an. 